\title{
XXII. Of the structure of living fabrics
}

\section{Rev. Patrick Keith F.L.S.}

To cite this article: Rev. Patrick Keith F.L.S. (1833) XXII. Of the structure of living fabrics , Philosophical Magazine Series 3, 2:8, 120-131, DOI: 10.1080/14786443308647985

To link to this article: http://dx.doi.org/10.1080/14786443308647985

册 Published online: 01 Jun 2009.

Submit your article to this journal $x$

LII Article views: 1

Q View related articles $\sqsubset$ 
As there must be an equal cone of rays incident upon the first surface of the crystal, I took other measurements with a view to determine its magnitude. For this purpose I placed a rough micrometer, consisting of two moveable metallic plates, immediately before the lens, and closed the plates, until on looking through the aperture on the second surface I could see them just touching the opposite sides of the circular images. The same thing was done for the interior circle of the annulus, and the focal length of the lens accurately measured. In this manner the extreme dimensions of the conical annulus were ascertained, and the true angle calculated. The mean of three such measurements gave $3^{\circ} 47^{\prime}$ for the corrected angle of the cone.

It has been observed that the theoretical angle of the cone has been computed from the three indices of refraction as determined by M. Rudberg. Now a very small error in the determination of these indices, or a very minute difference between their values in different specimens of the same mineral, would make a considerable change in the angle. On the other hand, the effects of diffraction must in some degree modify the experimental results. And hence, though the measures were not taken with all the means to insure accuracy of which they are susceptible, it will be seen that their correspondence with theory is as close as could be reasonably expected.

XXII. Of the Structure of Living Fabrics. By the Rev. Patrick Keith, F.L.S.

[Continued from p. 16.]

(External Structure continued.)-The Branches.

THE Branches are the divisions of the trunk, or caudex ascendens, originating generally in the upper extremity, but often also along the sides. The primary divisions are again subdivided into secondary divisions, and these again into still smaller divisions till they terminate at last in slender twigs. In their insertion or distribution they are opposite, or alternate, or verticillate, or scattered. In their position they are vertical, that is, lying close to the stem; or spreading, that is, forming a conspicuous angle with the stem; or divergent, that is, expanding horizontally; or deflected, that is, hanging down so as to form an arch, as in the Weeping Ash, or Willow. In their size they are proportioned to the dimensions of the trunk, expanding in trees of large growth to a great distance from the centre, and forming a sort of secondary trunk. The horizontal branches of a full-grown Calabash-tree are said to 
be from forty to fifty feet in length*; while the horizontal branches of what is called the Live-oak, of East Florida, are said to extend to upwards of fifty paces + .

The most beautiful specimens that England affords, of plants with wide-spreading branches, are undoubtedly those of the Beech-tree; and the finest we have ever had an opportunity of admiring, are those in Eastwell Park, Kent, a seat of the Earl of Winchelsea. Expanding their aged and venerable arms in the full maturity of their growth, dignified in their elevation, and clothed with the pleasing verdure of their glossy leaves, they excite in the breast of the spectator emotions approaching to those of the sublime; and yet they are not so conspicuously remarkable for vastness of dimension as for beauty and symmetry of contour. The measurement of one of the handsomest of them was as follows: girth of the trunk, close to the soil, from eighteen to twenty feet; height, clear of branches, from seven to eight feet; horizontal growth of the lower branches, thirty-six feet, which, with half the width of the stem, gives a semidiameter of thirty-nine feet, and consequently a diameter of seventy-eight feet; slanting extent of the upper branches, such as to give to the group a sort of globular contour, as regular as if it had been clipped with shears, with an estimated elevation of from fifty to sixty feet. Think of the cooling and delightful shade afforded by this ample expansion, as filled up with its summer garniture of leaf and fiower, and you have a type before you similar to that from which Virgil drew when he said or sang,

Tityre, tu patule recubans sub tegmine fagi,

Sylvestrem tenui Musam meditaris avena.-Eclog. i. 1.

Indeed we are of opinion that no reader of Virgil is competent to form a correct or adequate idea of the beauty of the distich now quoted, till he has seen some such trees as those now described. The Beech-trees of Knowle Park, near Seven Oaks, are said to be of dimensions still larger; and the farfamed Beeches of Knockholt are said to be the largest in England.

The Leaf.-The leaf, which belongs to the division of the temporary parts of the plant, is a thin and flat substance, of a green colour, issuing generally from the extremity of the branches, but sometimes also immediately from the stem or root, and distinguishable by the sight or touch, into an upper and under surface, a base and an apex, with a midrib and lateral nerves. Yet leaves are not always thin and flat, nor are they always green. The leaves of the Aloe are thick and fleshy; and the leaves of the several species of Beet-root are

* Fanil. des Plant. Pref. ccxii. Third Series. Vol. 2. No.8. Feb. 1833.
+ Bartram's Travels. $\mathbf{R}$ 


\section{2}

Rev. P. Keith on the Structure of Living Fabrics.

of a dark and dull purple. Neither are they always furnished with transverse or lateral nerves. These are proper to Dicotyledonous plants only, for in Monocotyledonous plants the nerves are all parallel. The point by which the leaf is attached to the plant, is the base; the opposite and terminating point is the apex; the intermediate body of the leaf is the expansion, and the boundary of the leaf is the margin. It often happens that the base of the leaf is prolonged into a sort of semi-cylindrical pedicle, by which the expansion is removed to some distance from the point of attachment, as in the Vine and Poplar. This pedicle is denominated the footstalk or petiole, entering the expansion generally by the margin, but sometimes also by the centre, as in Nasturtium. In Populus tremula it is compressed in a line at right angles to the expansion, which peculiarity some phytologists regard as the cause of the leaf's mobility *.

'The figure of the leaf or expansion has been found to be of great use to botanists in the discriminating of the several species of a genus; and hence they have spared no pains to determine by observation and description its varieties of form. Linnæus enumerates more than a hundred $t$. If the expansion is flat and membranaceous, the most frequent forms are the circular, the oval, the oblong, the triangular; if thick and succulent, the most frequent forms are the cylindrical, the semicylindrical, the sword-shaped, the compressed. The apex is acute, or obtuse, or bitten, or truncated, as in the leaves of the Tulip-tree. The margin is entire, or notched, or toothed, or serrated. The expansion is entire, or cleft, or lobed; yet the figure of some leaves is altogether anomalous, and cannot be brought under any of the foregoing divisions. The leaf of Nepenthes distillatoria, which is itself lanceolate, terminates at the summit in a sort of thread-shaped pedicle, supporting a hollow and cylindrical, or rather pitcher-shaped appendage, to which there is attached the curious and peculiar process of a lid opening at one side. This appendage secretes a fluid which is said to be very pleasant to the taste. The leaf of Dioncea Muscipula is furnished with a process issuing from the apex, which has a slight resemblance to a steel trap with the wings expanded, This singular appendage is so highly irritable, that if it is but touched with the point of any fine or sharp instrument, or if an insect but alights upon it, the lobes immediately collapse as if eager to seize their prey, and detain the insect captive, so that it resembles a trap, to which it has been compared, not only in form but in function.

In their size, leaves exhibit as much variety as in their

* Cours de Phyiol. Séance, i. 24.

+ Phil. Bot., sect. 83. 
figure. But it is not always the largest plant that has the largest leaf. The leaf of Caltha palustris, though a humble herb, is larger than the leaf of the oak, though a lofty tree. The largest leaf produced by any species of British plant, is, as I believe, that of Arctium Lappa, or of Tussilago Petasites, which is often to be met with of the dimensions of upwards of twenty inches in length by eighteen at the greatest breadth. The leaves of Strelitzia Regina grow to a length of three or four feet, with a breadth of eighteen or twenty inches at the widest. The leaves of the Plantain-tree (Musa paradisiaca) have been known to grow to the extent of ten feet in length by two feet at the basis*; so that, owing, perhaps, to their extraordinary dimensions, some writers have supposed them to be the leaves of which Adam and Eve are said to have made themselves aprons, when they first felt the want of clothing $t$. But the largest of all simple leaves is, doubtless, that of the Talipat-tree (Corypha umbraculifera), a native of Ceylon, said to be often met with of such a magnitude as to measure not less than eleven feet from the base to the apex, by sixteen feet across at the widest part, giving, thus, an ample circumference of nearly forty feet, and forming, when fully expanded, a most capacious and efficient parasol.

The leaves of trees, from their size or number, are naturally well calculated to form an agreeable and cooling shade, amidst the sultry heats of the intra-tropical regions,

\section{............ where broad Palmettos shower}

Delicious coolness in the shadowy bower;-(Mont; romery's West Indies.) and even in countries that are not within the tropics the shade afforded by the leaves of trees is still extremely desirable during the heats of summer. Hence the soft and balmy slumbers which an ancient poet experienced under the cool and delightful shade of the Plane-tree;

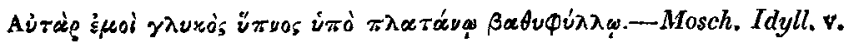
Hence also the celebrity of the groves of Academus, where Plato and his successors delivered their lectures in philosophy, and instilled into the minds of their youthful followers the love of truth :

Scilicet ut possem curvo dignoscere rectum,

Atque inter sylvas Academi quærere verum.-Hor. Epist. I. lib. ii. 44.

The odour of many plants, which is extremely grateful to the smell, as well as their virtues, whether medical or dietetical, is very frequently contained in the leaf. Lastly, as the leaf is merely a temporary or deciduous part, it dies in the autumn or winter, and is regenerated in the succeeding spring,

* Lour. Flor. Cochin.

+ Gen. iii. 7. 
exhibiting an apt and edifying emblem of the succession of human generations, according to the beautiful remark of the greatest of all poets:

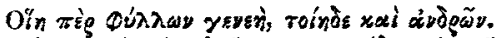

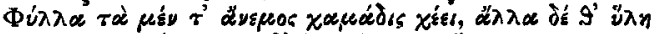

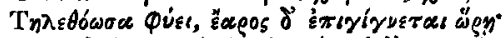

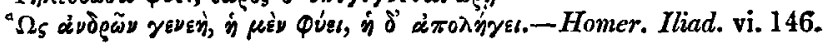

While it exists, however, it forms one of the principal ornaments of the plant, clothing it with verdure and covering it with grace; and even in its decay and fall it ceases not to gratify the eye, assuming, by slow degrees, a paler and a milder shade, and tingeing the forest and the plain with an infinite variety of hues.

The Bulb.-The bulb, an appellation borrowed from the Latin term bulbus, a round or bulbous root,-

Candidus Alcathoï qui mittitur urbe Pelasga

Bulbus, et ex horto quae venit herba salax,-(Ovid. Art. Am. lib. ii. 42.)

is a soft succulent substance, of an oval or globular figure, containing the rudiments of a future plant, and situated upon the root, stem, or branch, from which it ultimately and spontaneously detaches itself, and forms a new individual. If situated upon the root, it is said to be radical; if upon the stem or branches, it is said to be caulinary. The radical bulb therefore is not a root; but it is, as Linnæus has well defined it, "the winter quarters of the future plant *," furnished with a root suitable to its peculiar structure; that is, with an apparatus of radical fibres issuing from its base. It is solid, as in Crocus sativus; or coated, as in Allium Cepa; or scaly, as in Lilium candidum.

The caulinary bulb originates in the axis of the leaves, as in Dentria bulbifera; or at the base of the umbel of flowers, as in Allium carinatum. In either case it is nourished by the parent plant till it reaches maturity, when the bond of connexion is dissolved, and the bulb falls to the ground, endowed with the capacity of striking root in the soil, by sending out fibres from the base, and so converting itself into a new plant. The flowers of bulbous plants have great beauty, -a property of which poets, as well as florists, have always known how to avail themselves. If Anacreon has a wreath or a garland to weave, he is sure to insert into it a due proportion of lilies; and so are also the modern sons of song.

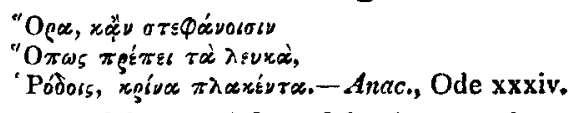

Some bulbs are useful as articles of food, or rather as giving

- Phil. Bot, p. 50. sect. 85. 
a seasoning to food, such as the Common Onion; others are useful in medicine, such as the Squill or Sea Onion; and all of them are peculiarly tenacious of potential life if excluded from the action of the atmosphere. An Egyptian mummy that was lately unswathed in this country, was found to grasp in its hand a bulbous root. When exposed to the atmosphere, it germinated; and when placed in the soil, it grew with great rapidity*. It could not have been less than two thousand years old.

The Bud.-The bud is a small and ovate or conical-shaped substance, issuing from the axis of the leaves, or extremity of the branches, and containing the rudiments of future branches, leaves, or fruit; but not detaching itself spontaneously from the plant and forming a new individual. It is composed externally of a number of concave and overlapping scales, that protect the inclosed germ from the injuries of the atmosphere, and is connected with the stem or branch by means of a short and fleshy pedicle, in which the scales originate. The bud of the American Walnut is said to be the most magnificent of all known examples, though the bud of the Horse Chestnut ( $\mathbb{E}$ isculus Hippocastanum) is, as I believe, but little inferior to it.

Buds produce leaves only, or flowers only, or leaves and flowers together. The two former varieties may be seen in the buds of the Peach-tree; the latter, in those of the Horse Chestnut. Yet all plants are not furnished with buds. Annuals and many shrubs have none; and even trees and shrubs to which they are proper, do not produce buds in hot climates. But in this country and in all cold countries, trees and shrubs are universally furnished with buds; and without the intervention of a bud, no new part is added to the plant. Buds have not been found to be of much use to botanists in the discrimination of species, though they may serve occasionally to distinguish plants in the winter ; and gardeners do, in fact, distinguish almost all their plants by the bud.

The Flower.-The flower, which, like the leaf, belongs to the division of the temporary parts of the plant, is an organ that issues generally from the extremity of the branches, but sometimes also from the root, stem, and even leaf; being the apparatus destined by nature for the production of the fruit, and being distinguishable, for the most part, by the brilliancy of its colouring, or the sweetness of its smell. It has been happily styled by Pliny, The joy of plants, - Flos gaudium arborum †; of which the Lily, the Tulip, and the lovely Rose, so sweetly sung by Anacreon of old, are magnificent examples :

* Jcurn. of Royal Instit., Oct. 1830.

$\dagger$ Hist. Nat., lib. xvi, cap. xxv. 
'Pódoy ás Qígio roy änos,

'Pódor हैa

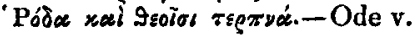

One of the most splendid of all known flowers is that of the Laurel Magnolia, of East Florida, which, when fully expanded, gives a width across measuring not less than from six to nine inches*. But a much larger flower still is that of Aristolochia cordifolia, which is said to give a breadth across of at least sixteen inches. This is enormous; and yet it is little in comparison of the extraordinary and gigantic dimensions of the fully expanded flower of Rafflesia Arnoldi, which displays a diameter, as ascertained by actual measurement, of not less than three feet + .

Flowers, in their mode of attachment, are either sessile, as in Agrimony, or supported upon a peduncle, as in the Cowslip. In their direction they are upright, or bending, or nodding, or unilateral, that is, attached to one side only of the stem, as in Lily of the Valley. If they issue from the root, they are radical; if from the stem, caulinary; if from the branch, ramial; if from the leaf, foliary, as in Ruscus. But in all their varieties, they are obviously divisible into the following distinct parts, - the calyx, the corolla, the stamens, the pistil.

The Calyx, - an appellation borrowed from the Greek term

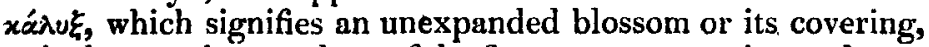
-is the exterior envelope of the flower, encompassing and protecting the interior parts. It may be perceived very distinctly in a Rose not yet fully blown, or in a Poppy beginning to open. Yet it is not to be regarded as altogether essential to the idea of a flower, for in many flowers it is wanting. The Tulip has no calyx. But in the flowers of perfect plants it is very generally present under the modification of perianth, glume, or scale. The perianth is a calyx that encircles the flower completely, and often assumes the similitude of a cup. In the case of the Acorn, the similitude is perfect. It is either proper to a single flower, as in Primula ; or common to several flowers, as in Tragopogon. It consists of a single and undivided piece, as in Primula; or of several distinct pieces, as in Rumex. It is caducous or deciduous, or permanent and persistent, as in St. John's Wort. The glume is a chaffy and membranous substance, accompanying the flowers of the Grasses, and constituting their calyx, but not so formed as to resemble a cup. Yet, if it be true that there is no rule without an exception, a cup-shaped glume must exist. The outer covering of the flowers of Cornucopia cucullata has been thought to present that exception. But botanists seem

* Bartram's Travels.

+ Linn. Trans. vol. xiii. Part I. 
now agreed to regard it as an involucrum. The Scale is a thin, chaffy, and membranaceous substance, forming part of the fructification of a variety of plants that produce incomplete flowers, and constituting their calyx. It may be seen in the catkins of the Willow and in the cones of the Fir. In the former it is a proper calyx, in the latter it is a common calyx.

The Corolla is the interior envelope of the flower, investing the central parts, but invested by the calyx. It is generally of a finer and more delicate texture than the calyx, and is of all the parts of the fructification the most showy and ornamental, being always, or with but few exceptions, that which is the most highly coloured, as well as that from which the flower imparts its rich and fragrant perfume,-its croceos odores, -delighting at the same time both the sight and smell. Ta this most elegant part of the fructification, the term Corolla has been very happily applied by Linnæus, signifying as it does in the original, a crown or chaplet of flowers.

Et modo solvebam nostra de fronte corollas.-Propert.i. 5. 21.

Like the calyx, the corolla consists either of a single piece called a petal, or of several distinct pieces called petals. In the former case it is said to be monopetalous; in the latter case it is said to be dipetalous, tripetalous, or tetrapetalous, according to the number of distinct petals. The monopetalous corolla is regarded as divisible into three parts, - the tube, the mouth, the border. The tube is the lower portion, cylindrical and inflated. The mouth is the middle portion, often beset with fine hairs, or with small projecting scales, so as nearly to shut it up. The border is the upper and expanding extremity. In its general contour it is bell-shaped, or clubshaped, or funnel-shaped, or wheel-shaped. In the polypetalous corolla, each petal is regarded as divisible into a claw and border, the aggregate contour assuming many forms, amongst which the most remarkable are the cruciform and the papilionaceous. Like the calyx the corolla is not to be regarded as absolutely essential to the botanical notion of a flower, because, in some flowers, it is wanting. Yet, where one only of the two envelopes is present, it is sometimes a matter of considerable difficulty to say which of them it is. Is it a calyx, or is it a corolla? Botanists have laid down several rules on this subject, but no one that is quite satisfactory. In cases of doubt we must be guided by analogy.

The stamens, - an appellation borrowed from the Latin term stamen, a thread,-

Et gracili geminas intendunt stamine telas,-(Ovid. Met. vi. 54.) are substances of a very slender fabric, and of a thread-shaped 


\section{Rev. P. Keith on the Structure of Living Fabrics.}

figure, surmounted with a small bag or viscus, and situated immediately within the corolla, to which they are sometimes attached. A very good example of them may be seen by opening up the blossom of a Tulip or of a Lily. They are apparently of no importance in the eye of the vulgar spectator, but are essential to the botanical notion of a flower, because indispensable to the formation of perfect fruit. The calyx is sometimes wanting, and the corolla is sometimes wanting; or the calyx and corolla both, as in Euphorbia; but the stamens are never wanting, except through adventitious or accidental causes. On the number of stamens, Linnæus has founded the first twelve classes of his artificial method; so that if any flower is furnished with but one stamen, it is to be referred to the first class; if with two, to the second class; if with three, to the third, and so on in succession. The remaining classes are founded on other peculiarities.

Stamens are usually regarded as consisting of two parts, -a filament and an anther. Yet the filament is not an indispensable part of the apparatus of a flower. There are many flowers without a filament, but no flower without an anther. It is a viscus of one or nore cells containing a powder, which botanists denominate the pollen, and which, at the period of the nuaturity of the flower, bursts its integuments and explodes.

The pistil is a small and column-shaped, but often pestleshaped substance, occupying almost invariably the centre of the flower, and encompassed immediately by the stamens, that is, when the plant is hermaphrodite. In monocious and dicecious plants, this arrangement cannot take place. It is solitary as in the Cherry, or multiplicate as in the Apple and Pear; and is divisible, at least, into two, but very often into three distinct parts, - the ovary, the style, and the stigma. The Ovary is the lower extremity of the pistil, supporting the style and stigma, and containing the rudiments of the fruit. In its attachment, it is sessile or stipitate, inferior or superior; and in its figure it is globular, or egg-shaped, or oblong, or compressed, as in the Vetch. The Style, the middle portion of the pistil, is a prolongation of the substance of the ovary, issuing generally from its upper extremity, and supporting the stigma. It is deciduous, and falls when the ovary is ripe or permanent, and adheres to the fruit. The Stigma is a small and glandular-looking substance, crowning the style, and hence also denominated the summit. Yet it is sometimes, though rarely, lateral, as in Scheuchzeria. In its figure it is globular, or hemispherical, or conical, or petaloid; and in its duration it is like the style, sometimes deciduous, and sometimes persistent.

Flowers are often found to be furnished with certain addi- 
tional and supernumerary parts, denominated appendages; such as the involucre, the spathe, the bracte, the nectary. The first three are analogous to leaf or calyx, and demand no particular notice in our present brief view. The latter is analogous to corolla, and is peculiar both in its form and function. It is defined to be an appendage of the flower secreting or containing a honied juice. Its function was detected by Malpighi, but he gave it no name*. This was reserved for Linnæus, who applied to it the very appropriate appellation of nectarium - the nectary or honey-cup, from nectar, the drink of the gods.

\author{
Illum ego lucidas \\ Inire sedes, ducere nectaris \\ Succos, et assribi quietis \\ Ordinibus patiar Deorum.-Hor. lib. iii. Ode iii.
}

It assumes a great variety of shapes and situations in different genera of plants, and resembles a horn, or a cylinder, or a slipper, or a cowl, or a petal, or a pore, or a gland. It is attached generally to the corolla, but occasionally to the receptacle, or calyx, or stamens; and even to the anther or pistil, as in Adenanthera, and Cheiranthus.

The Fruit.-In the progress of fructification, when the several organs of the flower have discharged their respective functions, the petals, the stamens, the style, and often also the calyx, wither and fall.

Nec viola semper, nec hiantia lilia florent,

Et riget amissâ spina relicta rosâ.-Ovid. De Art. Amat. lib. ii. 115.

The ovary alone remains attached to the plant, and swells and expands till it reaches maturity. It is now denominated the fruit. In popular language the term is confined chiefly to such fruits as are esculent, as the Apple, the Peach, and the Cherry; but with the botanist, the matured ovary of every flower, with the parts contained, constitutes the fruit. Hence the position or distribution of the fruit upon the plant will be the same with that of the flower which preceded it; radical, if the flower was radical; terminal, if the flower was so. The figure of the fruit exhibits a very great variety of modifications, which it would be tedious to enumerate. But the spherical, or elliptical, or cylindrical forms are, perhaps, the most common. The size of the fruit is also very various, yet not at all in proportion to the plant producing it. The Oak and the Ash, though among the largest of trees, produce a fruit that is comparatively very small; while the Gourd, whose stem is but herbaceous and creeping, produces a fruit of a most enormous bulk. The surface of the fruit is very generally smooth,

- Anat. Plant. 47.

Third Series. Vol. 2. No. 8. Feb.1833. S 
and in many cases exquisitely coloured; so that the beauties of the departed flower have but given way to the beauties of the ripened fruit; the mellow tints of autumn being equally pleasing with the bloom of spring, and the complexion of the Peach and Apricot being nothing inferior to that of the blossom which preceded them.

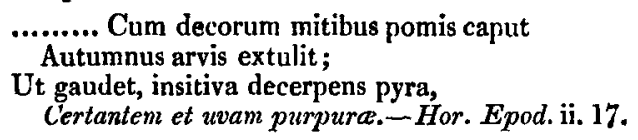

Fruits may be regarded as composed of two distinct and constituent parts, - the pericarp, and the seed. The Pericarp is the exterior portion of the ripened ovary, constituting, for the most part, its principal mass. Pericarps are distributed by botanists into the following species, though several of the terms are applied to the fruit also,- the capsule, the pome, the berry, the drupe, the silique, the legume, the cone. The capsule is a dry and membranaceous pericarp, separating when ripe into valves. 'The pome is a fleshy pericarp, inclosing a capsule, as in the familiar case of the Apple or Pear. The berry is a soft and pulpy pericarp, containing one or more seeds, but not inclosing a capsule. The drupe is a soft and pulpy pericarp, inclosing a nut; it is exemplified in the Cherry and Peach. The silique and legume are pods of different species, the one exemplified in Shepherd's Purse, the other in the Pea. The cone or strobile is the scales of the catkin, as exemplified in the genus Pinus.-The Seed, the last and most noble part of the fruit, is the interior portion of the ripened ovary, contained within the pericarp, and containing the rudiments of a new plant similar to that from which it sprang. In the Pea and Bean it is that part of the fruit which is eaten. In the Apple it is that part which is rejected and lodged within the core. Its figure, like that of the flower and fruit, is very much diversified. It is globular, or egg-shaped, or oblong, or kidney-shaped, or lenticular. Its magnitude is estimated by four cardinal points, instituted by botanists, and serving as a gauge or standard, through the application of which it is regarded as being large, middle-sized, small, or minute. It is smooth as in Linum, or furrowed as in Vinca, or wrinkled as in Dianthus inodorus, and is susceptible of the same modifications of shade as the flower and fruit. In Pæonia it is of a deep or dark purple; in Croton cayanospermum, it is of an azure blue; in Abrus precatorius it is of a rich scarlet; and in Coix, it is white as snow. On the surface of the seed, and at the point of its attachment to the pericarp, there is always to be found a mark or scar, differing in colour and in grain 
from the rest of the surface. It is the scar left by the natural fracture of the umbilical cord. Linnæus gave it the appellation of the Hilum, which the term scar translates.

The number of seeds produced by a single flower is extremely different in different plants. In some plants a flower produces only one seed; in others two, in others three, and in others many. But the great fertility of some species is altogether astonishing. A single stalk of Zea Mays will produce two thousand seeds*; a single plant of Inula Helenium, three thousand; and a single spike of Typha major, ten thousand. A single plant of 'Tobacco has been found, by calculation, to produce the almost incredible number of $360,000+$; a single stalk of Spleen-wort has been thought, by estimation, to produce at least a million of seeds.

Like bulbs, seeds are also extremely tenacious of potential life. If well preserved from the action of the atmosphere, they will retain their vitality for thousands of years. Among the mummies lately unswathed in this country, one was found to grasp in its hand some grains of Egyptian wheat. When put into the soil they germinated, and grew, and sprang up, as if they had been the produce of the year preceding.- So much for the external structure of perfect plants.

[To be continued.]

\section{Proceedings of Learned Societics.}

\section{ROYAL SOCIETY.}

Address of His Royal Highness the President, delivered at the Anniversary Meeting, Nov. 30, 1832.

Gentiemen,

THIS is the Second Anniversary of my election to the Chair of the Royal Society, and I gladly avail myself of the opportunity which it affords me of renewing the expression of my gratitude to you for the distinguished honour conferred upon me in electing me to it, and still more for the continued kindness and support which I have received from you in the execution of the duties of my office. I can only assure you, Gentlemen, that if it be your pleasure that I should continue to fill this Chair, I shall feel an additional motive to induce me to devote my most earnest attention to the promotion of the interests of the Society, in the perfect reliance which I place upon your cooperation and assistance, and in the confident expectation which I entertain, that in case I should fail in the due and efficient discharge of any of my duties, I shall experience from you the most kind and liberal interpretation of my motives and conduct.

In making my acknowledgments to the Fellows of the Society at

* Linn. Phil. Bot., sect. 132. 